\title{
On the functionalization of benzo[e][2,1]thiazine
}

\author{
Kirill Popov ${ }^{*}$, Tatyana Volovnenko and Julian Volovenko
}

\section{Full Research Paper}

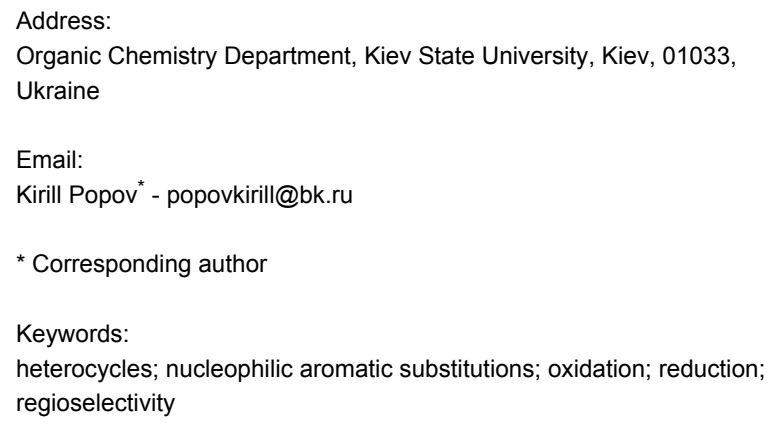

Beilstein Journal of Organic Chemistry 2009, 5, No. 42. doi:10.3762/bjoc.5.42

Received: 27 May 2009

Accepted: 26 August 2009

Published: 02 September 2009

Editor-in-Chief: J. Clayden

(C) 2009 Popov et al; licensee Beilstein-Institut.

License and terms: see end of document.

\section{Abstract}

The reactions of benzo[e][2,1]thiazine-4-chloro-3-carbaldehydes $\mathbf{1}$ and benzo[e][2,1]thiazine-4-chloro-3-carbonitriles 2 with a number of oxidizing and reducing agents are reported. A number of new, highly functionalized benzo[e][2,1]thiazine derivatives having potential biological activity were synthesized and described.

\section{Introduction}

Many derivatives of benzothiazine exhibit biological activity that ranges from antipsychotic [1] to anti-inflammatory [2], depending on the substituents present $[3,4]$. However, medicinal applications are limited as a consequence of side effects $[5,6]$. Much research has been carried out over the last 20 years with a view to improving benzothiazine-based drugs and to avoid the adverse effects [6,7].

In previous work $[8,9]$ we reported the synthesis of some novel benzothiazines, in particular benzo[e][2,1]thiazine derivatives, the $\beta$-chloroaldehydes 1 and $\beta$-chloronitriles 2 (Figure 1); their chemistry was shown to be quite versatile. Compounds $\mathbf{1}$ and $\mathbf{2}$ both contain 1,3-dielectrophilic fragments, which are C-4 carbon atoms of the benzothiazine ring and carbonyl group or nitrile function, respectively. Thus, further investigation of alde- hydes 1 and nitriles 2 should provide new benzo[e][2,1]thiazine derivatives, which can be used as intermediates for the synthesis of more elaborate compounds with potential biological activity.

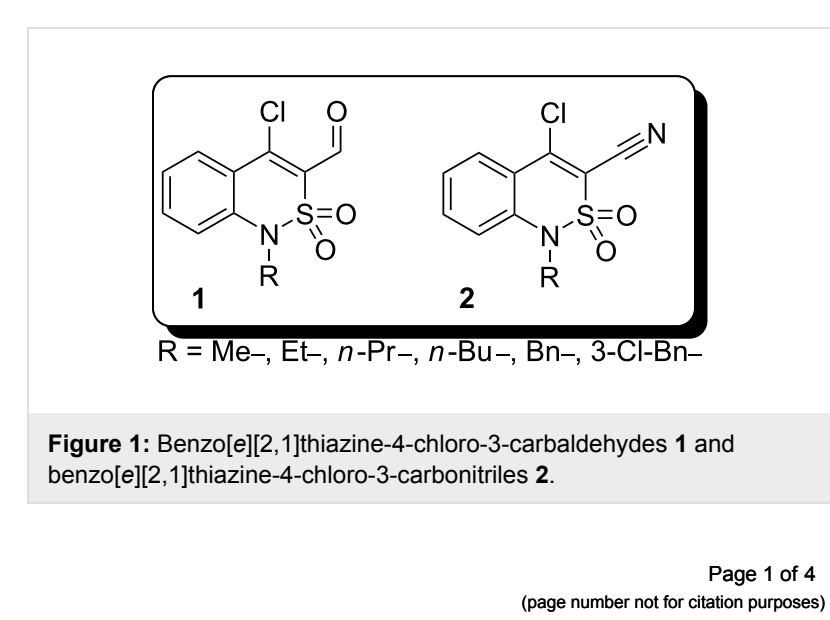


The current article describes the chemical behaviour of chloroaldehydes 1a,b and chloronitriles $\mathbf{2 a , b}$ (Table 1) in oxidation and reduction reactions.

Table 1: Chloroaldehydes $\mathbf{1 a , b}$ and chloronitriles $\mathbf{2 a , b}$.

\begin{tabular}{ccc} 
& Label & $\mathrm{R}$ \\
\hline 1a & $\mathbf{2 a}$ & $-\mathrm{Me}$ \\
1b & $\mathbf{2 b}$ & $-\mathrm{bt}$
\end{tabular}

\section{Results and Discussion}

Chloroaldehydes $\mathbf{1 a , b}$ are readily reduced under mild conditions by sodium borohydride to yield the alcohols $\mathbf{3 a}, \mathbf{b}$. Treatment of compounds $\mathbf{3 a}, \mathbf{b}$ with thionyl chloride in dry benzene results in the formation of dichloro derivatives $4 \mathbf{a}, \mathbf{b}$, whilst the 3-bromomethyl derivatives $\mathbf{5 a , b}$ are obtained by refluxing $\mathbf{3 a , b}$ in concentrated hydrobromic acid. Nucleophilic substitution of the chlorine atoms in compounds $\mathbf{4}$ shows similar behaviour. Thus, treatment of the dichloro derivatives $\mathbf{4 a}, \mathbf{b}$ with sodium methoxide gives a mixture of substitution products in a $2: 1$ isomer ratio with side-chain substitution predominating. The bromine atom in compounds $\mathbf{5}$ is much more reactive than the chlorines in $\mathbf{4}$. Thus, when $\mathbf{5 a}, \mathbf{b}$ were heated with 2-mercaptoethanol and triethylamine in dioxane, compounds $\mathbf{6 a}, \mathbf{b}$ were obtained as the sole products (Scheme 1).

Amines $\mathbf{7 a}, \mathbf{b}$ were synthesized by reduction of chloronitriles 2a,b with lithium aluminium hydride in dry diethyl ether or THF. Compounds 7 are very unstable. Presumably, intermolecular arylation of the active amino group occurs rapidly. Consequently, amines 7a,b were isolated as their hydrochlorides (Scheme 2).

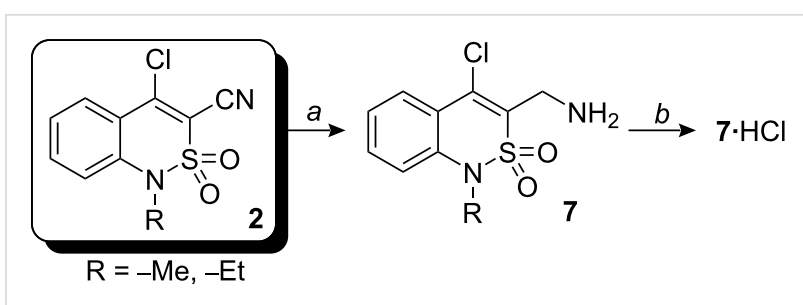

Scheme 2: $a$ : $\mathrm{LiAlH}_{4}$ (4 equiv), $\mathrm{Et}_{2} \mathrm{O}$ (THF), $3 \mathrm{~h}, 0^{\circ} \mathrm{C}$ to room temp.; $b$ $\mathrm{HCl}$ saturated in 1,4-dioxane.

Despite our expectations, aldehydes $\mathbf{1}$ appeared to be inert to the most common oxidizing agents. Thus, oxidants such as sodium dichromate and potassium permanganate did not transform 1 into the corresponding carboxylic acids. Attempted oxidation of compounds 1 with hydrogen peroxide, peroxyacetic acid and $m$-chloroperoxybenzoic acid ( $m$ CPBA) was also unsuccessful. The desired oxidation reaction occurs with silver(I) oxide, prepared in situ from silver nitrate. Aldehydes $\mathbf{1 a}, \mathbf{b}$ are oxidized under mild conditions; however, the resulting carboxylic acids $\mathbf{8}$ could not be isolated, since even at low temperatures (up to $3{ }^{\circ} \mathrm{C}$ ) and with immediate adjustment of the $\mathrm{pH}$ (between $\mathrm{pH}=10$ and $\mathrm{pH}=3$ ) instantaneous decarboxylation was observed, and 4-chlorobenzo[e][2,1]thiazines 9a,b were obtained in quantitative yield. The chlorine atom in compounds $\mathbf{9 a , b}$ is readily substituted by O-, N- and S-nucleophiles. Reaction of $\mathbf{9 a}, \mathbf{b}$ with sodium methoxide, benzylamine, and 2-mercaptoethanol gave the corresponding 4-methoxybenzothiazines 10a,b, $N$-benzylamines 11a,b and sulfanylethanol derivatives 12a,b, respectively (Scheme 3).

\section{Conclusion}

In summary, we describe the preparation of novel benzo[e][2,1]thiazine derivatives capable of further modification. In particular $\beta$-hydroxymethylchlorides $\mathbf{3 a , b}$, amines $\mathbf{7 a , b}$

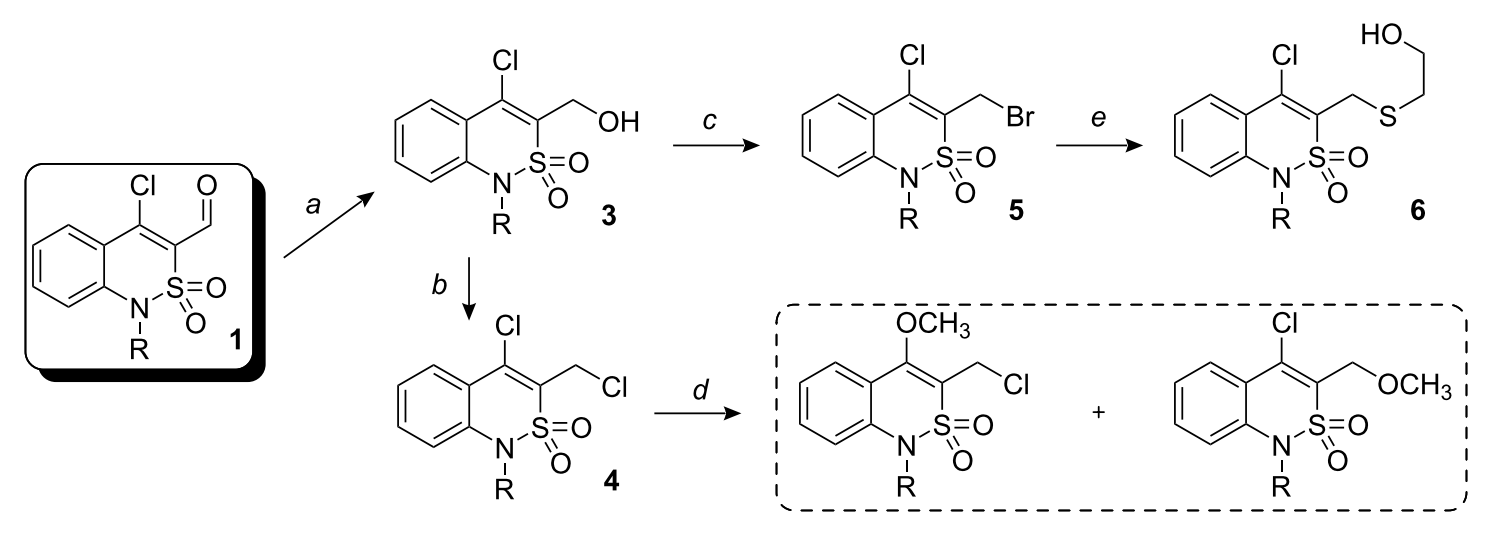

Scheme 1: a: $\mathrm{NaBH}_{4}$ (2.5 equiv), $\mathrm{MeOH}, 2 \mathrm{~h}$, room temp.; $b$ : $\mathrm{SOCl}_{2}$ (4 equiv), benzene, $3 \mathrm{~h}, 0{ }^{\circ} \mathrm{C}$ to room temp.; $c: \mathrm{HBr}(50 \%), 5 \mathrm{~h}, \mathrm{reflux} ; \mathrm{d}$ : $\mathrm{NaOMe}$ $\mathrm{MeOH}, 2 \mathrm{~h}$, reflux; e: $\mathrm{HS}-\left(\mathrm{CH}_{2}\right)_{2}-\mathrm{OH}$ (1.5 equiv), $\mathrm{K}_{2} \mathrm{CO}_{3}, 1,4$-dioxane, TEA, $2 \mathrm{~h}$, reflux. 


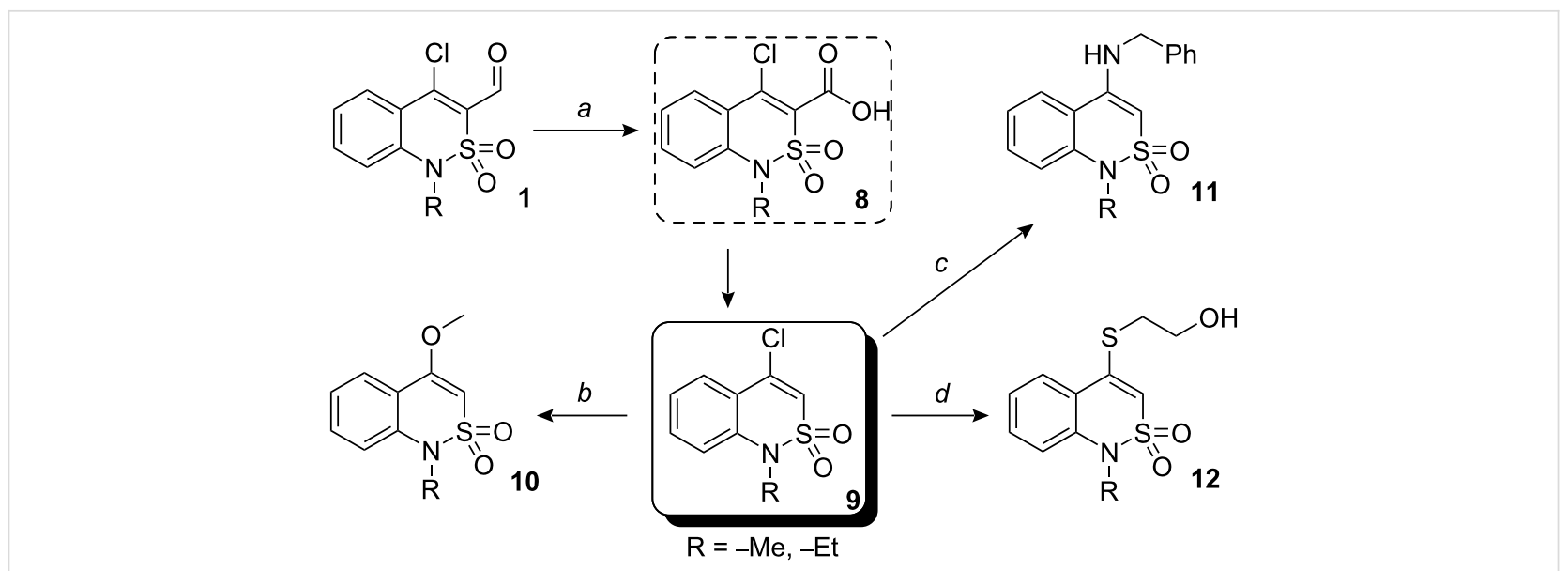

Scheme 3: a: $\mathrm{AgNO}_{3}$ (1.5 equiv), $\mathrm{NaOH}, \mathrm{H}_{2} \mathrm{O} / \mathrm{CH}_{2} \mathrm{Cl}_{2}, 3 \mathrm{~h}$, room temp.; $b$ : $\mathrm{NaOMe} / \mathrm{MeOH}, 1 \mathrm{~h}$, reflux; $c$ : $\mathrm{PhCH}_{2} \mathrm{NH}_{2}(2$ equiv), i-PrOH, 2 h, reflux; $d$ : $\mathrm{HS}-\left(\mathrm{CH}_{2}\right)_{2}-\mathrm{OH}$ (1.5 equiv), $\mathrm{K}_{2} \mathrm{CO}_{3}$, dioxane, TEA, $1 \mathrm{~h}$, reflux.

and 4-chlorobenzo[e][2,1]thiazines $\mathbf{9 a , b}$ were obtained in high yields (95-99\%) via convenient protocols involving oxidation and reduction reactions of compounds $\mathbf{1}$ and 2. Biological testing of the synthesized compounds is currently in progress. The structures of all the described products (Table 2) were established from their NMR spectra, elemental analyses and mass spectra.

Table 2: Representative compounds prepared via Schemes 1, 2 and 3.

\begin{tabular}{lll} 
Product label & \multicolumn{2}{c}{ Yield (\%) } \\
\cline { 2 - 3 } & $\mathbf{a}(\mathrm{R}=-\mathrm{Me})$ & $\mathbf{b}(\mathrm{R}=-\mathrm{Et})$ \\
\hline $\mathbf{3}$ & 93 & 95 \\
$\mathbf{4}$ & 95 & 98 \\
$\mathbf{5}$ & 71 & 76 \\
$\mathbf{6}$ & 55 & 57 \\
$\mathbf{7}$ & 67 & 68 \\
$\mathbf{9}$ & 99 & 99 \\
$\mathbf{1 0}$ & 85 & 87 \\
$\mathbf{1 1}$ & 60 & 63 \\
$\mathbf{1 2}$ & 32 & 34
\end{tabular}

\section{Experimental}

\section{General procedure for the synthesis of compounds 3}

To a magnetically stirred suspension of $\mathbf{1 a , b}(1 \mathrm{~g}, 4 \mathrm{mmol})$ in dry methanol $(5 \mathrm{~mL})$ sodium borohydride $(0.64 \mathrm{~g}, 16 \mathrm{mmol})$ was added in small portions at room temperature. The solution was stirred for 2 hours and concentrated in vacuo. Dilute hydrochloric acid $(2 \mathrm{~N} \mathrm{HCl}, 5 \mathrm{~mL})$ was added, the solid product filtered off and washed with water to give pure compound 3a,b (93-95\%).

\section{General procedure for the synthesis of compounds 4}

To a magnetically stirred suspension of $\mathbf{3 a}, \mathbf{b}(1 \mathrm{~g}, 3.6 \mathrm{mmol})$ in dry benzene $(6 \mathrm{~mL})$ thionyl chloride $(1.5 \mathrm{~mL})$ was added dropwise at room temperature. The solution was stirred for 3 hours and concentrated in vacuo. Water was added and the solid product filtered off. Pure $\mathbf{4 a , b}$ was obtained by crystallization from hexane (95-98\%).

\section{General procedure for the synthesis of compounds 5}

The mixture of $\mathbf{3 a}, \mathbf{b}(1 \mathrm{~g}, 3.6 \mathrm{mmol})$ and concentrated hydrobromic acid $(3 \mathrm{~mL})$ was refluxed for 5 hours. The reaction mixture was cooled to $0{ }^{\circ} \mathrm{C}$, the solids filtered off and washed with water to give pure compound $\mathbf{5 a , b}(71-76 \%)$.

\section{General procedure for the synthesis of compounds 6}

The mixture of compound 5a,b (1 g, $2.6 \mathrm{mmol})$, mercaptoethanol $(0.5 \mathrm{~mL})$, potassium carbonate $(0.5 \mathrm{~g})$ and triethylamine $(1.5 \mathrm{~mL})$ in 1,4-dioxane $(5 \mathrm{~mL})$ was refluxed for 2 hours, then concentrated in vacuo to afford the crude product as a brown oil. The pure product $\mathbf{6 a}, \mathbf{b}$ was obtained by column chromatography $\left(\mathrm{CHCl}_{3} / \mathrm{CH}_{3} \mathrm{OH} 9: 1,55-57 \%\right)$.

\section{General procedure for the synthesis of compounds 7}

To a magnetically stirred suspension of $\mathbf{2 a}, \mathbf{b}(1 \mathrm{~g}, 4 \mathrm{mmol})$ in dry ether $(3 \mathrm{~mL})$ or dry THF $(3 \mathrm{~mL})$ lithium aluminium hydride $(0.7 \mathrm{~g}, 16 \mathrm{mmol})$ was added in small portions at $0{ }^{\circ} \mathrm{C}$. The solution was stirred for 3 hours and the temperature gradually raised to $25{ }^{\circ} \mathrm{C}$. The solvent was evaporated and water added to the residue. The product was extracted with $\mathrm{CH}_{2} \mathrm{Cl}_{2}(3 \times 5 \mathrm{~mL})$, concentrated in vacuo and treated with dry 1,4-dioxane satur- 
ated with $\mathrm{HCl}$ to afford the pure crystalline product $7 \mathbf{a}, \mathbf{b}$ $(67-68 \%)$.

\section{General procedure for the synthesis of compounds 9}

To a magnetically stirred aqueous solution of silver nitrate $(1 \mathrm{~g}$, $6 \mathrm{mmol})$ sodium hydroxide $(0.3 \mathrm{~g}, 7.5 \mathrm{mmol})$ was added in small portions at room temperature. To the resulting suspension of $\mathrm{Ag}_{2} \mathrm{O}$ a solution of $\mathbf{1 a}, \mathbf{b}(1 \mathrm{~g}, 4 \mathrm{mmol})$ in $\mathrm{CH}_{2} \mathrm{Cl}_{2}(3 \mathrm{~mL})$ was added dropwise and the resulting mixture stirred for 3 hours. The organic layer was separated and concentrated in vacuo to give the pure solid product $9 \mathbf{a}, \mathbf{b}(99 \%)$.

\section{General procedure for the synthesis of compounds 10}

The mixture of 9a,b $(1 \mathrm{~g}, 4 \mathrm{mmol})$ and $\mathrm{MeONa}(0.5 \mathrm{~g}, 8.5$ mmol) in dry methanol $(5 \mathrm{~mL})$ was refluxed for 1 hour. The solvent was evaporated and the solid product washed with i-PrOH to give pure compound 10a,b $(85-87 \%)$.

\section{General procedure for the synthesis of compounds 11}

The mixture of 9a,b (1 g, $4 \mathrm{mmol})$ and benzylamine (0.5 g, 5 $\mathrm{mmol})$ in i-PrOH $(5 \mathrm{~mL})$ was refluxed for 2 hours. The solvent was evaporated, and the solid product washed with i-PrOH and water. The pure product 11a,b was obtained by crystallization from toluene $(60-63 \%)$.

\section{General procedure for the synthesis of compounds 12}

The mixture of 9a,b (1 g, $4 \mathrm{mmol})$, mercaptoethanol $(0.5 \mathrm{~mL})$, potassium carbonate $(0.5 \mathrm{~g})$ and triethylamine $(1.5 \mathrm{~mL})$ in $1,4-$ dioxane $(7 \mathrm{~mL})$ was refluxed for 1 hour. Inorganic material was removed by filtration and the resulting solution concentrated in vacuo. The oily product was purified by column chromatography on silica gel with chloroform-methanol (8:2) as eluent to give the pure product 12a,b (32-34\%).

\section{Supporting Information}

Supporting information contains melting points, elemental analyses, ${ }^{1} \mathrm{H}-,{ }^{13} \mathrm{C}-\mathrm{NMR}$ and mass spectra data for all new compounds (3-12).

\section{Supporting Information File 1}

Spectroscopic data for: On the functionalization of benzo[e][2,1]thiazine.

[http://www.beilstein-journals.org/bjoc/content/ supplementary/1860-5397-5-42-S1.doc]

\section{References}

1. Yeung, P.; Hubbard, J.; Korchinski, E.; Midha, K. Eur. J. Clin. Pharmacol. 1993, 45, 563-569. doi:10.1007/BF00315316

2. Olkkola, K. T.; Brunetto, A. V.; Mattila, M. J. Clin. Pharmacokinet. 1994, 26, 107-120. doi:10.2165/00003088-199426020-00004

3. Catsoulacos, P.; Camoutsis, C. J. Heterocycl. Chem. 1979, 16, 1503-1524. doi:10.1002/jhet.5570160801

4. Banerjee, R.; Chakraborty, H.; Sarkar, M. Spectrochim. Acta, Part A 2003, 56, 1213-1222. doi:10.1016/S1386-1425(02)00300-1

5. Rossi, S., Ed. Australian Medicines Handbook 2006; Australian Medicines Handbook Pty Ltd: Adelaide, 2006.

6. Van Hecken, A.; Schwartz, J. I.; Depre, M.; De Lepeleire, I.; Dallob, A.; Tanaka, W.; Wynants, K.; Buntinx, A.; Arnout, J.; Wong, P. H.; Ebel, D. L.; Gertz, B. J.; De Schepper, P. J. J. Clin. Pharmacol. 2000, 40, 1109-1120.

7. Chan, C.-C.; Boyce, S.; Brideau, C.; Charleson, S.; Cromlish, W.; Ethier, D.; Evans, J.; Ford-Hutchinson, A. W.; Forrest, M. J.; Gauthier, J. Y.; Gordon, R.; Gresser, M.; Guay, J.; Kargman, S.; Kennedy, B.; Leblanc, Y.; Leger, S.; Mancini, J.; O’Neill, G. P.; Ouellet, M.; Patrick, D.; Percival, M. D.; Perrier, H.; Prasit, P.; Rodger, I.; Tagari, P.; Therien, M.; Vickers, P.; Visco, D.; Wang, Z.; Webb, J.; Wong, E.; Xu, L.-J.; Young, R. N.; Zamboni, R.; Riendeau, D. Pharmacol. Exp. Ther. 1999, 290, 551-560.

8. Volovenko, Y. M.; Volovnenko, T. A.; Popov, K. S. J. Heterocycl. Chem. 2007, 44, 1413-1420. doi:10.1002/jhet.5570440627

9. Volovenko, Y. M.; Volovnenko, T. A.; Popov, K. S. Tetrahedron Lett. 2009, 50, 1171-1172. doi:10.1016/j.tetlet.2008.10.101

\section{License and Terms}

This is an Open Access article under the terms of the Creative Commons Attribution License (http://creativecommons.org/licenses/by/2.0), which permits unrestricted use, distribution, and reproduction in any medium, provided the original work is properly cited.

The license is subject to the Beilstein Journal of Organic Chemistry terms and conditions:

(http://www.beilstein-journals.org/bjoc)

The definitive version of this article is the electronic one which can be found at: doi:10.3762/bjoc.5.42 